\title{
HHV-8 Subtypes in South Africa: Identifcation of a Case Suggesting a Novel B Variant
}

Florette K. Treurnicht, ${ }^{1,4}$ Susan Engelbrecht,, ${ }^{1,4}$ Maureen B. Taylor, ${ }^{2}$ Johan W. Schneider, ${ }^{3,4}$ and Estrelita Janse van Rensburg ${ }^{1,4 *}$

${ }^{1}$ Department of Medical Virology, University of Stellenbosch, Tygerberg, South Africa

${ }^{2}$ Department of Medical Virology, University of Pretoria, South Africa

${ }^{3}$ Department of Anatomical Pathology, University of Stellenbosch, Tygerberg, South Africa

${ }^{4}$ Tygerberg Hospital, South Africa

\begin{abstract}
Human herpesvirus 8 (HHV-8) has been identified as the causative agent for all forms of Kaposi's sarcoma and is also associated with the development of body cavity-based B-cell lymphomas and multicentric Castleman's disease. HHV-8 genomes are now classified into five major subtypes $(A-E)$ that reflect sequence heterogeneity in the highly variable open reading frame (ORF) K1. To identify HHV-8 subtypes associated with different forms of Kaposi's sarcoma, we compared the ORF 26 and ORF-K1 gene sequences from South African patients with the prototype strains of the major subtypes, as well as published sequences from other African strains. DNA prepared from Kaposi's sarcoma biopsies and/or peripheral blood lymphocytes were available from 14 patients with postrenal transplant (iatrogenic) Kaposi's sarcoma, six patients with the African endemic form, and one patient with AIDS-related body cavity-based B-cell lymphoma. We identified a B2 subtype in six patients, four of whom also had a novel B5 type ORF 26 polymorphism. Two patients had B2 type patterns for both the ORF 26 and ORF-K1 genes. The ORF-K1 subtype A5 was identified in samples from three patients with a B3/C2 type polymorphism in the ORF 26 gene. A novel ORF-K1 B variant strain was identified in a patient with African endemic Kaposi's sarcoma, who also had a B3/C2 class ORF 26 pattern. In 58.3\% of iatrogenic Kaposi's sarcoma patients, a B5-type ORF 26 gene sequence pattern was identified. No association was found among particular subtypes, geographical origin of patients, or clinical presentation.
\end{abstract}

\section{INTRODUCTION}

Kaposi's sarcoma was first described in 1872. Four major clinical forms have since been described [Giraldo et al., 1989; Martin et al., 1993]: (1) epidemic or acquired immunodeficiency syndrome AIDS-associated; (2) classic; (3) African endemic; and (4) immunosuppressionassociated (iatrogenic) Kaposi's sarcoma [Giraldo et al., 1989; Beral et al., 1990; Martin et al., 1993]. African endemic Kaposi's sarcoma clusters among Africans from East and Central Africa and accounts for 3-18\% of all malignancies in these regions [Martin et al., 1993; Gompels and Kasolo, 1996; Lennette et al., 1996; Kasolo et al., 1997]. Since the start of the AIDS epidemic and the rapid spread of human immunodeficiency virus type $1(\mathrm{HIV}-1)$ in subSaharan Africa, differentiation between African endemic and epidemic Kaposi's sarcoma has become more difficult; presently the epidemic form is diagnosed predominantly in African patients [Matondo, 1995]. In South Africa, classic Kaposi's sarcoma is seen mostly in Jewish people of Eastern European (Ashkenazi) origin [Stein et al., 1994].

In 1994, human herpesvirus type 8 (HHV-8), originally called Kaposi's sarcoma-associated herpesvirus (KSHV), was identified as the etiologic agent for Kaposi's sarcoma [Chang et al., 1994; Moore et al., 1996]. HHV-8 is present in all Kaposi's sarcoma lesions and is also associated with the rare AIDS-related body cavity-based B-cell lymphoma, non-AIDS- 
associated body cavity-based B-cell lymphomas, and multicentric Castleman's disease [Cesarman et al., 1995, 1996; Boshoff et al., 1995; Huang et al., 1995; Soulier et al., 1995]. HHV-8 was detected in $8 \%$ of infants $<15$ months of age in Zambia, where a linear increase in seroprevalence with age was noticed that reflects the endemic nature of HHV-8 infection (47\% in 14-19-year-olds to $71 \%$ in persons aged $\geq 50$ years) [Kasolo et al., 1997; Olsen et al., 1998]. A high seroprevalence rate of $84-100 \%$ was also found in the non-Kaposi sarcoma endemic regions of West Africa (The Gambia and the Ivory Coast) [Lennette et al., 1996].

The diversity of HHV-8 genomes was based initially on sequence heterogeneity in the open reading frame (ORF) 26 and ORF 75 genes [Zong et al., 1997]. Only 1.5-2\% sequence variations were seen in these areas, and viral strains were subsequently classified into three main groups: $A, B$, and $C$. A novel subtype (subtype $N$ ) based on the ORF 75 gene was recently identified in $20 \%$ of the circulating strains in the African Black population of South Africa [Alagiozoglou et al., 2000].

The ORF-K1 gene has since been identified as the area with the highest sequence variability [Nicholas et al., 1998]. So far four subtypes (A, B, C, and D) and at least 13 distinct variants were identified on the basis of sequence heterogeneity. More recently, it was found that a novel subtype (subtype $E$ ), closest to the $D$ subtype, was circulating in an isolated population of the Brazilian Amerindians [Biggar et al., 2000]. Subtypes A, B, and C correspond to those of the initial classification based on the ORF 26 gene heterogeneity [Zong et al., 1999]. Subtype D was identified in samples from Taiwan and New Zealand, while individuals from sub-Saharan Africa are infected predominantly with subtype B genomes [Zong et al., 1999].

The ORF-K1 gene contains two variable regions: variable region 1 (VR1) and variable region 2 (VR2). The first B subtypes identified were from patients in the United States and had characteristic MAVKL-like sequences in the VR2, whereas B subtypes identified in samples from sub-Saharan Africa had characteristic TAFKT-like sequences. These variants were subsequently called B1 and B2 variants, respectively (G.S. Hayward, personal communication).

In order to identify the circulating strains of HHV-8 in South Africa, we analysed the ORF-K1 and 26 regions of the virus genome from patients with different clinical presentations and geographical origins.

\section{MATERIALS AND METHODS}

\section{Patients and Samples}

Formalinfixed, paraffin-embedded tissue blocks were available from 14 patients with postrenal transplant (iatrogenic) Kaposi's sarcoma seen at Tygerberg Hospital in the Western Cape [Moosa et al., 1998]. Fresh-frozen tissue samples and peripheral blood lymphocytes collected after remission of Kaposi's sarcoma lesions were also available from these patients. The presence of HHV-8 in these patients' samples was confirmed in a previous study [Moosa et al., 1998]. Fresh-frozen Kaposi's sarcoma biopsy samples were also available from six individuals with African endemic Kaposi's sarcoma seen at the Kalafong and Themba Hospitals in Gauteng and Mpumalanga Provinces, respectively. The mean age of the patients with African endemic Kaposi's sarcoma at diagnosis was 64.5 years (Table I). Peripheral blood lymphocyte and body cavity-based B-cell lymphoma samples were also available from a patient with AIDS seen at Tygerberg Hospital. 
TABLE I. Demographic and Clinical Data of South African Patients With HHV-8-Associated Diseases

\begin{tabular}{|c|c|c|c|c|c|}
\hline Patient & Age (yr) & Sex & Race & Clinical disease & Geographic origin \\
\hline TBF1 & 27 & Male & Mixed ancestral origin & IKS & Western cape \\
\hline TBF2 & 44 & Female & Mixed ancestral origin & IKS & Western cape \\
\hline TBF3 & 50 & Male & African Black & IKS & Western cape \\
\hline TBF4 & 48 & Female & Mixed ancestral origin & IKS & Western cape \\
\hline TBF5 & 56 & Male & African Black & IKS & Western cape \\
\hline TBF6 & 50 & Female & African Black & IKS & Western cape \\
\hline TBF8 & 36 & Female & Mixed ancestral origin & IKS & Western cape \\
\hline TBF10 & 41 & Male & Mixed ancestral origin & IKS & Western cape \\
\hline TBF11 & 30 & Male & Mixed ancestral origin & IKS & Western cape \\
\hline TBF12 & 39 & Male & Mixed ancestral origin & IKS & Western cape \\
\hline TBF13 & 43 & Female & Caucasian & IKS & Western cape \\
\hline TBF14 & 40 & Female & Mixed ancestral origin & IKS & Western cape \\
\hline TBB1 & 52 & Male & African Black & AIDS-BCBL & Western cape \\
\hline MP1 & 57 & Male & African Black & AKS & Mpumalanga \\
\hline MP3 & 76 & Male & African Black & AKS & Mpumalanga \\
\hline MP4 & 81 & Male & African Black & AKS & Mpumalanga \\
\hline MP5 & 67 & Male & African Black & AKS & Mpumalanga \\
\hline MP6 & 79 & Female & African Black & AKS & Mpumalanga \\
\hline MP10 & 27 & Male & African Black & AKS & Gauteng \\
\hline
\end{tabular}

TBF, Tygerberg Hospital renal transplant patients; TBF1-TBF14 correspond to patients 1-14 in Moosa et al. [1998]; TBB1, Tygerberg Hospital body cavity-based B-cell lymphoma patient; MP, African endemic KS (AKS) cases from Themba and Kalafong Hospitals; IKS, iatrogenic KS; AIDS-BCBL, AIDS-associated body cavity-based B-cell lymphoma.

\section{DNA Preparation}

DNA was prepared from paraffin-embedded tissue sections as described previously [van Rensburg et al., 1996, Moosa et al., 1998]. The QIAamp tissue and QIAamp blood kits (Qiagen $\mathrm{GmbH}$, Germany) were used to isolate DNA from fresh skin biopsies, peripheral blood lymphocytes, and body cavity-based B-cell lymphoma cells recovered from pleural fluid.

\section{Polymerase Chain Reaction}

Patient DNA samples were screened for HHV-8, using a nested polymerase chain reaction (PCR) method to amplify a 172-bp fragment of ORF 26 as described previously [Engelbrecht et al., 1997]. The following primers described previously [Kasolo et al., 1998; Cook et al., 1999], were used in various combinations to amplify the highly variable ORF K1 region from the different patient samples: the K1N pair, K1EX pair, K1/408/1, PMC20, and PMC21. The primer R408 (5'-GTA TTT AGT TTG TGA CAC GG) is the reverse complement of the K1/408/1 primer described previously [Cook et al., 1999]. The oligonucleotide sequences for three additional primers used [K1M1 (5'-GTG TGG AAC AAT CTG GG), OUGO1 (5'-CCT GTA CAA TCA AGA TGT TCC), and OUGO2 (5'-GTC AGT ACC AATC CACT G)] were kindly provided by T.F. Schulz, Department of Medical Microbiology, University of Liverpool.

Gene fragments containing the VR1 region were amplified by hemi- and nested PCR with the following primer sets: $\mathrm{K} 1 \mathrm{~N}$ forward/OUGO2 (outer pair) and $\mathrm{K} 1 \mathrm{~N}$ forward/R408 (inner pair); $\mathrm{K} 1 \mathrm{~N}$ forward/OUGO2 (outer pair) and $\mathrm{K} 1 \mathrm{~N}$ forward/K1EX reverse (inner pair); $\mathrm{K} 1 \mathrm{~N}$ forward/K1EX reverse (outer pair) and K1EX pair (inner pair); and OUGO1/OUGO2 (outer pair) and K1EX pair (inner pair). The following primer combinations were used to amplify gene fragments containing the VR2 region: K1M1/OUGO2 (outer pair) and K1/408/1/OUGO2 (inner pair); OUGO1/OUGO2 (outer pair) and K1/408/1/OUGO2 (inner pair); and PMC20/PMC21 and K1/408/1/PMC21 (inner pair) or K1/408/1/OUGO2 (inner pair). A single gene fragment containing both the VR1 and VR2 regions was amplified with the following primer sets: K1N forward/OUGO2 (outer pair) and OUGO1/OUGO2 (inner pair); OUGO1/OUGO2 (outer pair) and K1M1/OUGO2 (inner pair) or K1EX forward/OUGO2 (inner pair); and PMC20/PMC21 (outer pair) and OUGO1/OUGO2 (inner pair). The Expand High Fidelity enzyme system 
(Roche Diagnostics $\mathrm{GmbH}$, Germany) was used for all amplifications with $2.5-\mathrm{mM} \mathrm{MgCl}_{2}$ concentration and an annealing temperature of $45^{\circ} \mathrm{C}$.

\section{DNA Sequencing and Phylogenetic Analysis}

PCR products or product bands purified from agarose gel by the QIAEXII method (Qiagen) were directly sequenced using the $A B I$ Prism Dye Terminator Cycle sequencing kit (Perkin Elmer, CA). The nested primers were used as sequencing primers. Sequence data were captured and processed with the DNAMAN (Lynnon BioSoft, Quebec, Canada) software program. Nucleotide sequences were aligned with the CLUSTAL X software program [Thompson et al., 1997]. Kimura-2- parameter distance calculation, neighbour-joining tree construction, and bootstrap analysis were done with TREECON V1.36 software program [Van de Peer and De Wachter, 1994, 1997]. The sequences were deposited in the GenBank database under accession numbers AF387367-AF387378.

\section{RESULTS}

Classification of ORF 26 Polymorphisms Subgroups identified by distinct ORF 26 polymorphisms patterns are summarised in Table II. The ORF 26 gene could be sequenced in 12 of 14 iatrogenic Kaposi's sarcoma samples, and the polymorphisms seen were briefly reported previously [Moosa et al., 1998]. Only one patient of Caucasian origin, TBF13, had an ORF 26 prototype A pattern. Patients TBF6, MP4, MP6, and MP10 had ORF 26 group B3/C2 patterns. Viral strains from eight patients' samples showed a distinct B5 subgroup pattern. The B5 subgroup had a characteristic G!T change at position 1055 in addition to A!G and A!C changes at positions 1132 and 1139, respectively. Seven of 12 patients (58.3\%) with iatrogenic Kaposi's sarcoma and only one of six (16.7\%) patients with African endemic Kaposi's sarcoma had ORF 26 type B5 patterns. TBF11 demonstrated a B1 pattern, while TBF4, TBB1, MP3, and MP5 had B2-type patterns. Patient TBF3 had an unclassified variant B pattern. This patient showed the same characteristic pattern of polymorphisms as the B5 subgroup but had an additional $\mathrm{C} \rightarrow$ T change (silent mutation) at position 1077.

TABLE II. Analysis of Sequence Polymorphisms in the ORF 26 Gene of HHV- 8

\begin{tabular}{|c|c|c|c|c|c|c|c|c|c|c|}
\hline \multirow[b]{2}{*}{ Patient } & \multicolumn{9}{|c|}{ ORF 26 polymorphisms } & \multirow[b]{2}{*}{ Class $^{b-}$} \\
\hline & 1032 & 1055 & 1077 & 1086 & 1094 & 1103 & 1122 & 1132 & 1139 & \\
\hline$\overline{B C B L-R^{n}}$ & $\mathrm{C}$ & G & $\mathrm{C}$ & $\mathrm{C}$ & $\mathrm{G}$ & $\mathrm{C}$ & G & $\mathrm{A}$ & $\mathrm{A}$ & $\mathrm{A}$ \\
\hline TBF13 & - & - & - & - & - & - & - & - & - & $\mathrm{A}$ \\
\hline MP4 & - & - & - & $\mathrm{T}$ & - & - & - & - & $\mathrm{C}$ & $\mathrm{B} 3 / \mathrm{C} 2$ \\
\hline MP6 & - & - & - & $\mathrm{T}$ & - & - & - & - & $\mathrm{C}$ & $\mathrm{B} 3 / \mathrm{C} 2$ \\
\hline TBF6 & - & - & - & $\mathrm{T}$ & - & - & - & - & $\mathrm{C}$ & $\mathrm{B} 3 / \mathrm{C} 2$ \\
\hline MP10 & - & - & - & $\mathrm{T}$ & - & - & - & - & C & $\mathrm{B} 3 / \mathrm{C} 2$ \\
\hline MP1 & - & $\mathrm{T}$ & - & - & - & - & - & $\mathrm{G}$ & C & B5 \\
\hline TBF1 & - & $\mathrm{T}$ & - & - & - & - & - & $\mathrm{G}$ & C & B5 \\
\hline TBF2 & - & $\mathrm{T}$ & - & - & - & - & - & G & C & B5 \\
\hline TBF5 & - & $\mathrm{T}$ & - & - & - & - & - & $\mathrm{G}$ & $\mathrm{C}$ & B5 \\
\hline TBF8 & - & $\mathrm{T}$ & - & - & - & - & - & G & $\mathrm{C}$ & B5 \\
\hline TBF10 & - & $\mathrm{T}$ & - & - & - & - & - & G & C & B5 \\
\hline TBF12 & - & $\mathrm{T}$ & - & - & - & - & - & G & C & B5 \\
\hline TBF14 & - & $\mathrm{T}$ & - & - & - & - & - & G & C & B5 \\
\hline TBF3 & - & $\mathrm{T}$ & $\mathrm{T}$ & - & - & - & - & G & $\mathrm{C}$ & ? \\
\hline TBF11 & - & - & - & - & - & - & - & $\mathrm{G}$ & $\mathrm{C}$ & B1 \\
\hline TBF4 & $\mathrm{A}$ & - & - & - & - & - & - & G & $\mathrm{C}$ & $\mathrm{B} 2$ \\
\hline TBB1 & $\mathrm{A}$ & - & - & - & - & - & - & G & C & B2 \\
\hline MP3 & $\mathrm{A}$ & - & - & - & - & - & - & G & C & B2 \\
\hline MP5 & $\mathrm{A}$ & - & - & - & - & - & - & $\mathrm{G}$ & $\mathrm{C}$ & B2 \\
\hline
\end{tabular}

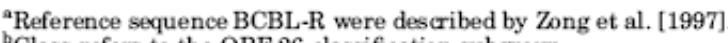

${ }^{\text {b}}$ Class refers to the ORF 26 classification subgroup.

\section{ORF-K1 Subgroups}

The ORF-K1 VR1 and VR2 amino acid sequence data from this study as well as the prototype and previously identified African strains are summarised in Figure 1. HHV-8 genomes from 
patients MP4, MP6, and TBF6 belong the ORF-K1 subtype A major subgroup with amino acid patterns characteristic of the A5 variant group. In the phylogenetic tree (Fig. 2), South African A5 variants cluster with those identified in patients from Northern Italy (IFe1, IFe5) and Uganda (Ug374). A novel genome type was identified in the viral strain from patient MP10. This strain's VR1 region of the ORF-K1 protein was almost identical to that of the B1 prototype strain except for one amino acid change near both ends. In the VR2 region, it had the characteristic MAVKLlike sequence at the beginning of VR2 and was essentially homologous to the B1 prototype strain, except for an 11-amino acid deletion from position 201-211, which suggests its classification as a novel B variant (Fig. 1).

Three patients with post-transplant Kaposi's sarcoma (TBF2, TBF5, TBF10), one with AIDSassociated body cavity-based B-cell lymphoma (TBB1), and two patients with African endemic Kaposi's sarcoma (MP1 and MP5), had the characteristic TAFKT-like sequence characteristic of the B2 variant type genomes at the beginning of VR2 (Fig. 1). In the phylogenetic tree analysis, the two South African strains (MP5 and TBB1) are similar and cluster together with Ugandan (Ug81 and Ugd1) strains (Fig. 2). The HHV-8 B2 genomes from TBF5, TBF10, and MP1 form a separate cluster from the other B2 type genomes (bootstrap value of 100\%). These B2 type genomes (TBF5, TBF10, MP1) all have a B5 type ORF 26 polymorphism. Only the VR2 region excluding the last five amino acids could be amplified and sequenced from patient TBF2, who also had a B5-type ORF 26 polymorphism.

\section{ORF-K1 PROTEIN'S VARIABLE REGIONS}

\begin{tabular}{|c|c|c|c|c|c|}
\hline Sample & & VR1 (52-92) & VR2 (191-231) & K1 & ORF26 \\
\hline Al & CNNTRLERP & TETTLFPVTI ACNFTCVEQSGHRQSIWITW HA & TGFRTFSTNS LVNIIHATTH DVVVVKEAKS THEHIELHFLV & A.1 & \\
\hline A4 & CNDTRLERL & TERTLFPVTI PCNFTCVEQSGHRQSIWITW HA & TGFRTFSTNS LVNIIH---- DVVVVKEAKS THFHIELHFLV & A4 & \\
\hline IFe1 & CNDTRLLRL & TDQSETVDTI TCNETCVEQS GHRQSIWITW NA & TGPRTVSTNS LVNIIHATNH DVVVVKEAKS TNPHIEVPELV & A.5 & \\
\hline IFe5 & CNDTRLWRL & TDQSETVATI TCNFTCVEQS GHRQSIWITW NA & TGFRTFSTNT LVNIIHATTH HVVVVKEAKS TNPHIEVEZLV & A. 5 & \\
\hline Ug 374 & CNDTRLWRL & TDQSETVATI TCNETCVEQS GHRQSIWITW NA & TGERTFSTNS LVNIIHATTH DVVVVKBAKS TNPHIEVPELV & A. 5 & \\
\hline MP4 & CNNTRRINRL & TKQLFTVAGI TCNFTCVEQS GHRQSIWITW NA & TGFRTFSTNS LVNIIHATTH DVVVVKEAKS TNPHIEVPPLV & A5 & $\mathrm{B3} / \mathrm{C} 2$ \\
\hline MP6 & CNDTRLWRL & TNQSETVANI TCNFTCVEQS GHRQSIWITW NA & TGFRTESTNS LVNIIHATTH DVVVVKEAKS TNPHIEVPFLV & A5 & $\mathrm{B} 3 / \mathrm{C} 2$ \\
\hline TBF 6 & CNDTRLWRL & TSQSSFTVAT TCNETCVEOS GHRQ̈SIWITW WA & 'TCFTTFSTMS LVNIIHATTH DVVVVKEAKS TNPHIEVPFLV & A5 & $\mathrm{B} 3 / \mathrm{C} 2$ \\
\hline B1 & CNGTQLHRI & TASNLTVSSL TCNETCMTTS GPTHSIWIQW YT & MAVKLLRTNG LLKIIPATTH AAVAVEEVKS TNTHIQVEFLV & B1 & \\
\hline MP10 & CNGTLLHRI & TASNLTVSSL TCNETCMTTS GPTHSIWIEW YT & MAVKVVRTAG L--------- --VAVEEVKS TNTHIQVPFLV & NB & $\mathrm{B} 3 / \mathrm{C} 2$ \\
\hline UgD 2 & CNGTQLRRI & RGSNLTVSLL TCNFTCMTAS GETHSIWIEW YT & TAFKMSRTNG LLKIIPATTH AAVAVEBVKS TNPHIQVPELV & B2 & \\
\hline Ug81 & CNGTRLHRI & TTSNLTVSLL TCNFTCMTTS GPTHSIWIEW YT & TTFKMSRTNG LLKIIPATTH AAVAVEEVKS TNPHIQVPELV & $\mathrm{B} 2$ & \\
\hline G51 & CNGTRLRRI & TASNLTVSGL TCNFTCMTTS GPTHSIWIEW YT & TAFKTLRTNG LLKIIPAT'TH AAVAVEEVKS TNPHIQVPELV & B2 & \\
\hline G71 & CNGTRINRT & TASNLTVSSL SCNFTCMTTS GPTHSIWIEW XT & TAFKKLRNNG LLKI IPATTH AAVAVEEVKS TNPHIQVPELV & B2 & \\
\hline G413 & CNGTRLLRI & TASNPTVCSL TCNFTCMTAS GPTHSIWIEW YT & TAFETLRTNG LLKIIPATTH AAVAVEEVKS TNPHIQVPELV & B2 & \\
\hline MP5 & CNGTQLWRI & RESTLTVSSL TCNFTCMTAS GPTHSIWIEW YT & TAFKISRTNG LLKIIPATTH AAVAVEEVKS TNPHIQVPFLV & B2 & B2 \\
\hline TBB1 & CNGTQLWRI & RESTLTVSSL TCNFTCMTAS GPTHSIWIEW YT & TAFKISRTNG LLKIIPATTH AAVAVEEVKS TNPHIQVPELV & B2 & B2 \\
\hline TBF2 & & & TAFKTLTTNG LLKIIPATTH AAVAVEEVKF TNSQIQ & B2 & B5 \\
\hline TBF5 & & & TAFKTLTTNG LLKIIPATTH AAVAVEEVKS TNPHIQVPELV & B2 & B5 \\
\hline TBF10 & & & TAFKTLRTAG LLKIIPATTH AAVAVEEVKS TNPHIQVPFLV & B2 & B5 \\
\hline $\mathrm{Cl}$ & CNDTRLFRL & THDTFTVVNF ICNESCVGQS GHRHSLWMTW YG & TGFRTFSTNS -- --HAT'TH DVV--KEAKF TNPHIEVPFLV & $\mathrm{cl}$ & \\
\hline $\mathrm{c} 3$ & CNDTRLLRL & TQQTFTVWAL ICNFSCVGQS GHRHSLWITW YP & TGFRTFSTNS -----AATTH DVLVMKEAKS TNLHIQVHEIV & $\mathrm{C} 3$ & \\
\hline D1 & CNGTRLLRI & TGATLTIPSL TGNFTCVDHS GLSHSIWIQR YP & TGETTESTNR LVNIIPATTH AVVVVEKVKS LHPHIEVPELV & D1 & \\
\hline
\end{tabular}

Fig. 1. Comparison of the ORF-K1 VR1 and VR2 region amino acid sequences from South African samples (in bold) with the consensus sequences for the various groups and subgroups. The VR1 region from MP1, TBF2, TBF5, and TBF10 could not be amplified. Sequences of the reference strains were obtained from Genbank database: A1 (AF133038), A4 (AF133039), B1 (AF133040), C1 (AF133041), C3
(AF133042), D1 (AF133043) [Zong et al., 1999]; Ug81 (AF130291), Ugd1 (AF130292), Ug374 (AF130289), IFe1 (AF130282), IFe5 (AF130284), G51 (AF130264), G71 (AF130265), G413 (AF130262) [Cook et al., 1999]. Dashes indicate amino acid deletions. NB, novel B variant. 


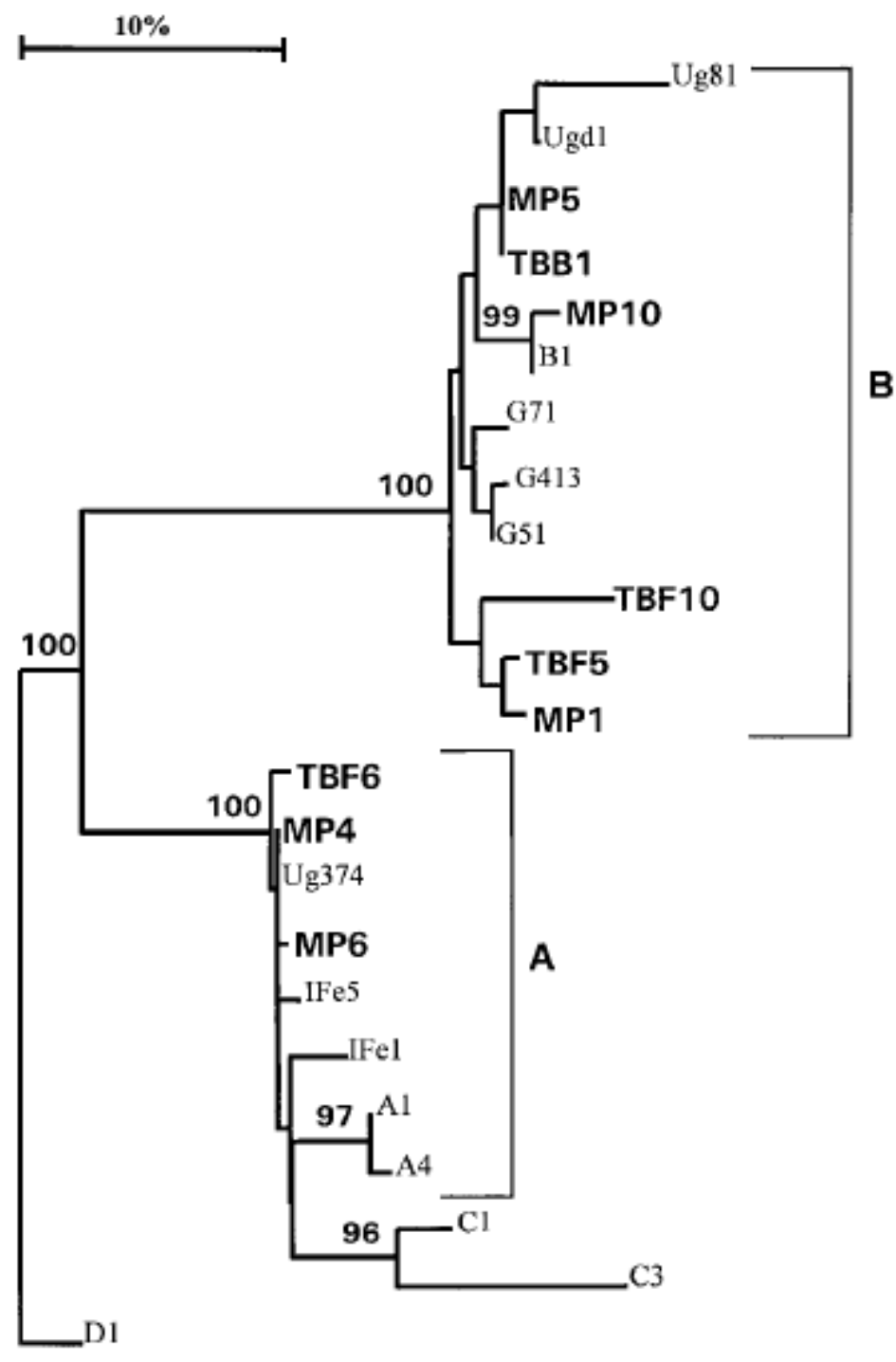

Fig. 2. Rooted phylogenetic tree analysis of partial ORF-K1 nucleot ide sequences that include the VR2 region and transmembrane domain of HHV-8 genomes from South African patients. The neighbour-joining method for tree construction is based on 395-bp sequences (insertions and deletions were not taken into account). Bootstrap values of $>90 \%$ are indicated at the branch nodes considered. The bar scale calculating sequence dissimilarity on the horizontal axis is shown. TBF2 was not included for phylogenetic analysis, as it did not meet the required sequence.

\section{DISCUSSION}

This is the first study to report on the genetic diversity of HHV-8 genomes originating from different geographic areas and clinical forms of Kaposi's sarcoma in South Africa. According to the ORF-K1 classification, six patients were subtype $B$ and three were subtype $A$. This is the first report of a novel B variant with an inframe deletion in VR2. Although the HHV-8 genome identified in patient MP10 showed homology to the B1 type genomes, the 33-bp deletion suggests its classification as a novel B variant. Inframe deletions have so far been described in the ORF-K1 subtype A4 variant and in all C subtype genomes [Cook et al., 1999; Zong et al., 1999]. B subtype genomes identified previously in African-Americans and individuals from African countries like Zaire, Tanzania, Uganda, and Zambia primarily belong to the B1 variant group [Poole et al., 1999; Zong et al., 1999]. It was however found that some genomes identified from Uganda and The Gambia belong to the B2 variant group [Cook et al., 1999; 
Zong et al., 1999]. These data showed that most B subtypes found in the South African patients were B2 variant strains, and no B1 variants were identified.

HHV-8 subtype A genomes with the distinct $A 5$ amino acid pattern in the $\mathrm{K} 1$ protein differ from other A variants by 6-8\% [Cook et al., 1999; Zong et al., 1999]. A5 type genomes were previously found in African patients [Cook et al., 1999, Zong et al., 1999], and in two patients from Northern Italy [Cook et al., 1999]. The HHV-8 genomes identified in HIV-negative and positive children from Zambia with Kaposi's sarcoma or febrile illnesses were also A5 variants [Kasolo et al., 1998, Poole et al., 1999]. Three of the South African patients belonged to this variant group; two of them cluster with HHV-8 genomes identified in patient samples from Northern Italy and Uganda [Cook et al., 1999]. A5 type ORF-K1 gene sequences were also previously documented in HHV-8 genomes from two South African patients [Poole et al., 1999].

We also found a novel B5 polymorphism in the ORF 26 gene sequences from $58.3 \%$ of our renal transplant patients. Three of these renal transplant patients, as well as two patients with African endemic Kaposi's sarcoma, had B2 type ORF-K1 genes. Distinct clustering of ORF 26 type B3/C2 polymorphisms were found in the HHV-8 genomes from Saudi Arabian renal transplant patients [Foreman et al., 1998], and they also belonged to the ORF-K1 subtype C [Poole et al., 1999]. In contrast, we identified ORF 26 type B3/C2 patterns in one patient with post-transplant Kaposi's sarcoma and two patients with the African endemic form who had A5 type ORF-K1 genes. A B3/C2 type ORF 26 gene polymorphism was also seen in the patient (MP10) with African endemic Kaposi's sarcoma who had the novel B type ORF-K1 gene. A similar B3/C2 ORF 26 and A5 ORF-K1 pattern was previously described in two African patients [Poole et al., 1999]. The ambiguity observed for the B3 and C2 type (B3/C2) ORF 26 pattern show that HHV-8 classification based on ORF 26 alone may be insufficient [Poole et al., 1999]. Linkage analysis studies involving the ORF 75, T0.7/ K12, K14.1, K15, and ORF-K1 genes of $\mathrm{HHV}-8$ revealed that chimerism do exist in HHV-8 genomes from various samples [Poole et al., 1999]. Poole and colleagues suggested that the B3/C2 type pattern might represent either true $B$ variants or mosaic genomes.

In this study, neither K1 nor ORF 26 subtypes had any characteristic geographical or clinical associations. The presence of the B3/C2 type ORF 26 pattern in our patients belonging to the A5 K1-subtype suggests the presence of chimeric HHV-8 genomes. Studies involving larger numbers of Kaposi's sarcoma patients need to be conducted to determine the incidence and significance of the novel B variant and A5 type infections in South Africa, as well as to determine the extent of chimerism in A5 type genomes. 


\section{REFERENCES}

Alagiozoglou L, Sitas F, Morris L. 2000. Phylogenetic analysis of human herpesvirus-8 in South Africa and identification of a novel subgroup. J Gen Virol 81:2029-2038.

Beral V, Peterman TA, Berkelman RL, Jaffe HW. 1990. Kaposi's sarcoma among persons with AIDS: a sexually transmitted infection? Lancet 335:123.

Biggar RJ, Whitby D, Marshall V, Linhares AC, Black F. 2000. Human herpesvirus 8 in Brazilian Amerindians: a hyperendemic population with a new subtype. J Infect Dis 181:1562-1568.

Boshoff C, Whitby D, Hatziioannou T, Fisher C, van der Walt J, Hatzakis A, Wess R, Schulz T. 1995. Kaposi's sarcoma-associated herpesvirus in HIV-negative Kaposi's sarcoma. Lancet 345:1043-1044.

Cesarman E, Chang Y, Moore PS, Said JW, Knowles DM. 1995. Kaposi's sarcoma-associated herpesvirus-like DNA sequences are present in AIDS-related body cavity based lymphomas. N Engl J Med 332:1186-1191.

Cesarman E, Nador RG, Aozasa K, Delsol G, Said JW, Knowles DM. 1996. Kaposi's sarcomaassociated herpesvirus in non-AIDSrelated lymphomas occurring in body cavities. Am J Pathol 149:53-57.

Chang Y, Cesarman E, Pessin MS, Lee F, Culpepper J, Knowles DM, Moore PS. 1994. Identification of herpes virus-like DNA sequences in AIDS-associated Kaposi's sarcoma. Science 266:1865-1869.

Cook PM, Whitby D, Calabro M-L, Luppi M, Kakoola DN, Hjalgrim H, Ariyoshi K, Ensoli B, Davison AJ, Schulz TF, and the International Collaborative Group. 1999. Variability and evolution of Kaposi's sarcoma-associated herpesvirus in Europe and Africa. AIDS 13:11651176.

Engelbrecht S, Treurnicht FK, Schneider JW, Jordaan HF, Steytler JG, Wranz PAB, van Rensburg EJ. 1997. Detection of human herpes virus 8 DNA and sequence polymorphism in classical, epidemic, and iatrogenic Kaposi's sarcoma in South Africa. J Med Virol 52:168-173.

Foreman KE, Alkan S, Krueger AE, Panella JR, Swinnen LJ, Nickoloff BJ. 1998. Geographically distinct HHV-8 DNA sequences in Saudi Arabian iatrogenic Kaposi's sarcoma lesions. Am J Pathol 153:1001-1004.

Giraldo G, Buonaguro FM, Beth-Giraldo E. 1989. The role of opportunistic viruses in Kaposi's sarcoma (KS) evolution. APMIS suppl 8:62-76.

Gompels UA, Kasolo FC. 1996. HHV-8 serology and Kaposi's sarcoma. Lancet 348:1587-1588.

Huang YQ, Li JJ, Kaplan MH, Poiesz B, Katabira E, Zhang WC, Feiner D, Friedman-Kien AE. 1995. Human herpesvirus-like nucleic acid in various forms of Kaposi's sarcoma. Lancet 345:577-578. 
Kasolo FC, Mpabalwani E, Gompels UA. 1997. Infection with AIDSrelated herpesviruses in human immunodeficiency virus-negative infants and endemic childhood Kaposi's sarcoma in Africa. J Gen Virol 78:847-856.

Kasolo FC, Monze M, Obel N, Anderson RA, French C, Gompels UA. 1998. Sequence analyses of human herpesvirus-8 strains from both African human immunodeficiency virusnegative and -positive childhood endemic Kaposi's sarcoma show a close relationship with strains identified in febrile children and high variation in the K1 glycoprotein. J Gen Virol 79:3055-3065.

Lennette ET, Blackbourn DJ, Levy JA. 1996. Antibodies to human herpesvirus type 8 in the general population and in Kaposi's sarcoma patients. Lancet 348:858-861.

Martin RW, Hood AF, Farmer ER. 1993. Kaposi's sarcoma. Medicine 72:245-260.

Matondo P. 1995. Clinical classification of African Kaposi's sarcoma: time for reappraisal. Int J Dermatol 34:166-167.

Moore PS, Gao S-J, Dominguez G, Cesarman E, Lungu O, Knowles DM, Garber R, Pellet PE, McGeoch DJ, Chang Y. 1996. Primary characterization of a herpes virus agent associated with Kaposi's sarcoma. J Virol 70:549-558.

Moosa MR, Treurnicht FK, van Rensburg EJ, Schneider JW, Jordaan HF, Engelbrecht S. 1998. Detection and subtyping of human herpesvirus-8 in renal transplant patients before and after remission of Kaposi's sarcoma. Transplantation 66:214-218.

Nicholas J, Zong J-C, Alcendor DJ, Ciufo DM, Poole LJ, Sarisky RT, Chiou C-J, Zhang X, Wan X, Guo H-G, Reitz MS, Hayward GS. 1998. Novel organizational features, captured cellular genes, and strain variability within the genome of KSHV/HHV8. Monog Natl Cancer Inst 23:7988.

Olsen SJ, Chang Y, Moore PS, Biggar RJ, Melbye M. 1998. Increasing seroprevalence with age in a highly Kaposi's sarcoma endemic region, Zambia in 1985. AIDS 12:1921-1925.

Poole LJ, Zong J-C, Ciufo DM, Alcendor DJ, Cannon JS, Ambinder R, Orenstein JM, Reitz MS, Hayward GS. 1999. Comparison of genetic variability at multiple loci across the genomes of the major subtypes of Kaposi's sarcoma-associated herpesvirus reveals evidence for recombination and for two distinct types of open reading frame $\mathrm{K} 15$ alleles at the right-hand end. J Virol 73:6646-6660.

Soulier J, Grollet L, Oksenhendler E, Cacoub P, Cazals-Hatem D, Babinet P, d'Agay MF, Clauvel JP, Raphael M, Degos L, Sigaux F. 1995. Kaposi's sarcoma-associated herpesviruslike DNA sequences in multicentric Castleman's disease. Blood 86:1276-1280.

Stein ME, Kantor A, Spencer D, Bezwoda WR. 1994. Classical Kaposi's sarcoma in Caucasians in Africa-experience at the Johannesburg Hospital (1978-1992). Dermatology 188:182-187.

Thompson JD, Gibson TJ, Plewniak F, Jeanmougin F, Higgins DG. 1997. The CLUSTAL_X windows interface: flexible strategies for multiple sequence alignment aided by quality analysis tools. Nucleic Acids Res 25:4876-4882. 
Van der Peer Y, De Wachter R. 1994. TREECON for Windows: a software package for the construction and drawing of evolutionary trees for the Microsoft Windows environment. CABIOS 10:569-570.

Van der Peer Y, De Wachter R. 1997. Construction of evolutionary distance trees with TREECON for Windows: accounting for variation in nucleotide substitution rate among sites. CABIOS 13:227-230.

van Rensburg E, Engelbrecht S, van Heerden WFP, Raubenheimer EJ, Schoub BD. 1996. Human papillomavirus DNA in oral squamous cell carcinomas from an African population sample. Anticancer Res 16:696-974.

Zong J-C,Metroka C, Reitz MS, Nicholas J, Hayward GS. 1997. Strain variability among Kaposi's sarcoma-associated herpesvirus (Human Herpesvirus 8) genomes: evidence that a large cohort of United states AIDS patients may have been infected by a single common isolate. J Virol 71:2505-2511.

Zong J-C, Ciufo DM, Alcendor DJ, Wan X, Nicholas J, Browning PJ, Rady PL, Tyring SK, Orenstein JM, Rabkin CS, Su I-J, Powell KF, Croxson M, Foreman KE, Nickoloff BJ, Alkan S, Hayward GS. 1999. High-level variability in the ORF-K1 membrane protein gene at the left end of the Kaposi's sarcoma- associated herpesvirus genome defines four major virus subtypes and multiple variants or clades in different human populations. J Virol 73: 4156-4170. 